\title{
Micro-level evaluation of socio-technological interventions to address climate change-induced stresses in dairy enterprises
}

\author{
Ritu Chakravarty ${ }^{1}, K_{\text {Ponnusamy }}{ }^{1}$ and R Sendhil ${ }^{2}$
}

Received: 13 April 2021 / Accepted: 19 July 2021 / Published online: 31 October 2021

(C) Indian Dairy Association (India) 2021

\begin{abstract}
The paper aims at micro-level evaluation of dairy centric socio-technological interventions under the Technology Demonstration Component (TDC) of the National Innovations in Climate Resilient Agriculture (NICRA) Project in Karnal, Yamunanagar and Sirsa districts of Haryana. The interventions were introduced to address the identified climate stresses under the project for enhancing resilience in dairy production. The study was conducted during 2015-16, employing Participatory Rural Appraisal (PRA) techniques to assess the farmers' feedback on climate change perception and their acceptance and satisfaction of introduced interventions, from the NICRA adopted village in each district. Ten socio-technological interventions were evaluated each based on two dimensions of perceived attributes and benefits sub-evaluation parameters. The reason based satisfaction was recorded on a farmer rating for each intervention. Among six introduced technological interventions, improved fodder crop varieties (total score 28 and 30) and area specific mineral mixture supplementation (total score 28 to 29) were perceived as highly beneficial in terms of sustained milk production even during periods of heat stress followed by moderate beneficial of interventions viz., Vitamin $\mathrm{E}$ supplementation, mustard oil supplementation and safe dung
\end{abstract}

\footnotetext{
${ }^{1}$ Dairy Extension Division, ICAR-National Dairy Research Institute, Karnal-132001, Haryana

${ }^{2}$ Agricultural Economics, ICAR-Indian Institute of Wheat and Barley Research, Karnal-132 001, Haryana

Ritu Chakravarty ( $\square)$

Dairy Extension Division, ICAR-National Dairy Research Institute, Karnal, Haryana and

E-mail: ritu.chakravarty@rediffmail.com
}

disposal through composting. Silage making intervention was perceived as low beneficial (total score 16). The Village Climate Risk Management Committee (VCRMC) was found as a highly beneficial (total score 27 to 30 ) social intervention, followed by women participation, contingency plan for climate change preparedness in fodder crops and preparation of season-centric milk products as moderate beneficial. The VCRMC was found highest satisfactory as rated by the farmers.

Keywords: Climate stresses, Dairy centric Interventions, Micro-level Evaluation, NICRA Project

\section{Introduction}

Animal husbandry continues to be a cornerstone for economic development as it accounts for about 26.2 per cent of the Gross Value Added (GVA) of agriculture and allied sector (GoI, 2019). The dairy farming sector is sensitive to climate which poses as a serious long-term challenge. The small holder farmers bear the major brunt of the undesirable effects of climate change and climate variability, as they often lack the adequate resources for adaptation to climate change. This severely curtails farm production, threatening the livelihood, food and nutritional security of the already marginalized households. The impact of climate change has predicted a fall in agricultural productivity of northern India to a tune of 25 per cent, between 2003 and 2080s (Cline, 2007). Further, the increase in frequency and intensity of extreme weather events cause severe socio-economic consequences particularly to the marginalized groups in society (Huvisa, 2012). Climate change exerts long term impacts on dairy farming in various ways such as heat stress in animals which could result in reduced feed intake and milk production, increase in disease incidence and decreased reproductive performance (Chakravarty et al. 2012). The most vulnerable people to climate change are most often the poorest, who lack effective coping strategies to deal with shocks and stresses and who have had to resort to ineffective responses (Daze, 2011).

The National Innovation in Climate Resilient Agriculture (NICRA) project was launched in 2011 by the Indian Council of Agricultural Research (ICAR) with the funding from the Ministry of Agriculture and Farmers Welfare, Government of India. The specific objective 
of the Technology Demonstration Component (TDC) of NICRA is to enhance the resilience of Indian agriculture (crops, livestock and fisheries) to climatic variability and climate change through demonstration of site-specific technological interventions on farmers' fields (Ponnusamy et al. 2019). Rural communities have always been working to adapt to change in climate as it gradually occurred over centuries, but farmers in their specific agricultural systems, would benefit highly from support to develop sound and location specific adaptation strategies (Allara et al. 2012). It is therefore important to analyze, the level of accrued benefits of dairy centric interventions from the farmer's perspective in the rural households (Ponnusamy and Pachaiyappan, 2018) in the project site. Such type of study has so far not been conducted to assess the interventions introduced in the livestock component under the umbrella of the NICRA project. Therefore, the present study was conducted to evaluate the dairy centric sociotechnological interventions at micro-level and also assess the level of satisfaction of the farmers on those socio-technological interventions for further adaptation planning in the TDC-NICRA adopted villages.

\section{Materials and Methods}

\section{Sampling}

The study was carried out in Karnal, Yamunanagar and Sirsa districts of Haryana, under the umbrella of the Technology Demonstration Component of the NICRA project during 201516. Three villages viz., Sohana in Karnal, Radauri in Yamunanagar and Rupana khurd in Sirsa district, adopted under the TDCNICRA project were purposively selected and 30 households were selected from each village.

Under the Technology Demonstration Component of the NICRA project, the climate related stresses were identified in the respective study area. Climate stress such as heat stress in dairy animals and fodder scarcity in Sohana village, long dry spell, terminal heat stress, depletion of ground water in Radaur village and drought, heat wave, salinity in Rupana khurd village were the major identified climate induced stresses in the livestock farming by the respective project team.

\section{Data Source}

The study employed mainly primary data from 90 households, collected by personal interview through a developed and pretested schedule encompassing the socio-economic profile viz., landholding, herd size, annual income from dairy farming and gross annual income from all sources of each farmer from the selected villages. Data on farmer feedback based micro-level evaluation, were collected through the Participatory Rural Appraisal (PRA) techniques using a semi-structured interview schedule and checklist on various parameters pertaining to components of perceived attributes and benefits of the introduced socio-technological interventions. For conducting the PRA, representative group of farmer participants comprising 15 farmers in each district who had participated in the technology demonstration (TD) programme was selected by ensuring at least three participants for each intervention. To gain insight to the climate related stresses impacting the district, the Principal Investigators of the TDC-NICRA project in the three districts were also interviewed.

\section{Socio-Technological interventions in the project site}

Ten socio-technological interventions in dairy enterprise were considered of which six technological interventions comprises of area specific mineral mixture supplementation, improved fodder crop varieties, vitamin E supplementation, supplementation of mustard oil, silage making and safe dung disposal through composting while four social interventions included Village Climate Risk Management Committee (VCRMC), preparation of season centric dairy products for farm women, women participation and contingency plan for climate change preparedness in fodder crops. Area specific mineral mixture supplementation was introduced in each adopted village of all the three districts. Improved fodder crop varieties were introduced in the same adopted village in Karnal (BL 42, Oats Kent, Sorghum SX 17, Bajra-Napier grass) and Yamunanagar (Berseem varieties HB1, HB2) district, three technological interventions (vitamin $\mathrm{E}$ supplementation, supplementation of mustard oil and safe dung disposal through composting) were introduced in the adopted village of Karnal district and silage making was introduced in the adopted village in Yamunanagar district. Among the social interventions, Village Climate Risk Management Committee (VCRMC) was considered for each adopted village of all the three districts and two social interventions were studied in the adopted village in Karnal and one in Yamunanagar district.

\section{Evaluation parameters for socio-technological interventions}

Seven parameters were considered for the evaluation of each technological intervention at micro level. Farmer feedback on interventions was generated on the perceived attributes of the interventions viz., ease in use $\left(\mathrm{X}_{1}\right)$, farm suitability $\left(\mathrm{X}_{2}\right)$, triability $\left(X_{3}\right)$ and relative advantage $\left(X_{4}\right)$ and perceived benefits in terms of low input requirement $\left(\mathrm{Y}_{1}\right)$, high or sustained production $\left(\mathrm{Y}_{2}\right)$ and more income $\left(\mathrm{Y}_{3}\right)$. Each of these parameters were allotted a highest score of 5.0, thus, perceived attributes $(\mathrm{Z1})=\sum \mathrm{X}_{\mathrm{i}(1 \mathrm{t} \text { to } 4)}$ Perceived benefits $(Z 2)=\sum Y_{i(1 \text { to } 3)}$ and total score for each technological intervention $=(\mathrm{Z} 1+\mathrm{Z} 2)=\sum \mathrm{X}_{\mathrm{i}(1 \mathrm{to} 4)}+\sum \mathrm{Y}_{\mathrm{i}(1 \mathrm{t} \text { to } 3}$ .Each technological intervention was thus evaluated based on maximum possible score of 35 . Seven parameters were also considered for the evaluation of each social intervention at micro level. The perceived attributes of the social interventions pertained to number of households benefitted in the village (X1), inclusion of all categories of farmers (X2), linkage required with 
government and other agencies (X3) and gender equity (X4) and the perceived benefits included perceived sustainability (Y1), benefits in terms of incentives / subsidies / services / information support / training (Y2) and relative advantage (Y3). Each of these parameters were allotted a highest score of 5.0, thus, perceived attributes $(Z 1)=\sum X_{i(1 \text { to } 4)}$ perceived benefits $(Z 2)=\sum Y$ and total score for each social intervention $=(Z 1+Z 2)=\sum X_{i(1 \text { to }}^{\mathrm{i}(1 \text { to } 3)}$ ${ }_{4)}+\sum Y_{i(1 \text { to } 3)}$. Each social intervention was thus evaluated based on maximum possible score of 35 . The intervention was categorized as high (total score $>26$ ), moderate (17.5 to 26) and low $(<17.5)$ based on $<50 \%,>50-75 \%$ and $>75 \%$ beneficial using mean and standard deviation.

\section{Rating of satisfaction on the introduced Socio-Technological interventions}

The satisfaction of the farmers on each socio-technological interventions in the study area was rated on a four points scale of 0 to 3 (no satisfaction, low satisfaction, moderate satisfaction and high satisfaction), on each intervention and their reasons of response were identified from the respective districts.

\section{Results and Discussion}

\section{Socio-economic profile of farmers}

The socio-economic profile of the farmers in the study area revealed that most of them belonged to the middle income category based on their dairy enterprise $(43.33 \%)$ and the total gross annual income of the most of the farmers $(40.00 \%)$ was found to be low (Table 1). Though a majority of the farmers (60 $\%$ ) were rearing medium herd size, yet, income was found to be low. One of the major reasons for this could be the climate adversities affecting the district. To ameliorate the climate impact, the introduction of socio-technological interventions was envisaged to promote resilient production and thereby help to sustain farmers' income.

The technological interventions were introduced in all animal holding categories ranging from small (up to 2.65 Standard Animal Unit) to large herd size (more than 6.41 Standard Animal Unit). For introduction of improved fodder varieties to address fodder scarcity, land was a prerequisite and all categories of land holding farmers were included ranging from marginal farmers (upto $1 \mathrm{ha}$ ) to large farmers (more than $10 \mathrm{ha}$ ).

Technological interventions: The technological interventions introduced for dairy enterprises are presented in Table 2.

Area specific mineral mixture supplementation: This technological intervention had been introduced in the NICRA adopted villages in three districts. Total score based on four perceived attributes and three perceived benefits as per farmer feedback ranged between 28 to 29 and the technology was rated high by the farmers in all the villages of three districts. Due to heat stress experienced by the dairy animals, their fertility was reduced and milk yield was decreased. The area specific mineral mixture components for $\mathrm{Cu}, \mathrm{Mg}$, Ca and $\mathrm{Zn}$ supplemented @ $50 \mathrm{gms} /$ day specially, during transition period, proved beneficial. Fertility rate of dairy animals was also reported to increase.

Improved fodder crop varieties: Improved fodder crop varieties of berseem (BL 42), Oat (Kent), Sorghum (SX 17), Bajra-Napier grass were demonstrated in the same NICRA adopted village in

Table 1 Distribution of respondents according to annual income from dairy farming, annual income from all sources, herd size and land size $(\mathrm{n}=90)$

\begin{tabular}{|c|c|c|c|}
\hline Category & $\begin{array}{l}\text { Annual Income from Dairy } \\
\text { Farming (Rs.) }\end{array}$ & $\mathrm{f}$ & $\%$ \\
\hline$\overline{\text { Low }}$ & Upto 8595 & 28 & 31.11 \\
\hline Middle & $>8595$ to 25109 & 39 & 43.33 \\
\hline Category & \multicolumn{3}{|c|}{ Annual Income from All Sources } \\
\hline Low & Upto 128516 & 36 & 40.00 \\
\hline Category & \multicolumn{3}{|l|}{ Standard Animal Unit (SAU) } \\
\hline Small & Up to 2.65 & 18 & 20.00 \\
\hline Medium & $>2.65$ to 6.41 & 54 & 60.00 \\
\hline Large & More than 6.41 & 18 & 20.00 \\
\hline Category & \multicolumn{3}{|l|}{ Land holding (ha) } \\
\hline Large & More than 10 ha & 16 & 17.78 \\
\hline
\end{tabular}


Karnal district. As per farmers' feedback, total score based on four perceived attributes and three perceived benefits was 30 and the technology was rated high in the adopted village of Karnal district. Improved fodder crop varieties (Berseem varieties HB1, HB2) were also demonstrated in the same adopted village in Yamunanagar district. As per farmers' feedback total score based on same perceived attributes and benefits was 28 and the technology was also rated high in the adopted village of Yamunanagar district too since the traditional berseem variety Mascavi suffered due to increased stem borer attack and HB 1 and HB 2 Berseem varieties were reportedly found to be resistant to stem borer attack, besides being fast growing and yielding nutritious and palatable fodder.

Supplementation of Vitamin E and Mustard Oil: The supplementation of Vitamin E @ 5 gm/day/animal and Mustard Oil supplementation of $50 \mathrm{ml} /$ day/animal were introduced in the NICRA adopted village in Karnal district only. As per farmers' feedback, the total score based on similar perceived attributes and benefits was 24 for Vitamin E supplementation and 26 for Mustard oil supplementation. Both the interventions were rated as moderate as per farmers' feedback. Feeding mustard oil during summer season for 3 months helps in overcoming negative energy balance and help in sustaining milk production. Problems such as the high incidence of mastitis, poor reproductive efficiency and suppressed immune status of the animals were reported to be improved as Vitamin E supplemented during the transition period, works as an antioxidant and improves the immunity.

Silage making: The silage making was introduced only in the NICRA adopted village in Yamunanagar district for ensuring the availability of fodder during lean season as a result of the impact of climate change on agriculture. The intervention was however rated low as per farmers' feedback as the total score based on similar perceived attributes and benefits was only 16 as, it scored less on ease of use, farm suitability and triability under perceived attributes and low on low input and more income under perceived benefits, too.

Safe dung disposal through composting: The intervention was introduced in the NICRA adopted village in Karnal district to discourage open dumping of dung on the road side and mitigating the menace of mosquitoes. In addition, this could also result in methane reduction and boost the crop yields due to better nutrient availability. The intervention was rated as moderate as based on perceived attributes and benefits the total score was only 22 . However, the farmers perceived this intervention to be cumbersome as it requires additional land and labour input.

Table 2 Evaluation of technological interventions introduced for dairy enterprise

\begin{tabular}{|c|c|c|c|c|}
\hline $\begin{array}{l}\text { Technological intervention in } \\
\text { dairy enterprise }\end{array}$ & District & $\begin{array}{l}\text { Total perceived } \\
\text { attributes } \\
\text { (Z1) }\end{array}$ & $\begin{array}{l}\text { Total perceived } \\
\text { benefits } \\
\text { ( Z2 ) }\end{array}$ & $\begin{array}{l}\text { Attributes }+ \\
\text { Benefits } \\
\text { (Total Score) } \\
\text { Z1 }+ \text { Z2 ) }\end{array}$ \\
\hline Area specific mineral mixture & Karnal & 19 & 10 & 29 \\
\hline \multirow{2}{*}{ supplementation } & Yamunanagar & 18 & 10 & 28 \\
\hline & Sirsa & 18 & 10 & 28 \\
\hline \multirow[t]{2}{*}{ Improved fodder crop varieties } & Karnal & 19 & 11 & 30 \\
\hline & Yamunanagar & 17 & 11 & 28 \\
\hline Vitamin E supplementation & Karnal & 15 & 9 & 24 \\
\hline Mustard oil supplementation & Karnal & 16 & 10 & 26 \\
\hline Silage Making & Yamunanagar & 9 & 7 & 16 \\
\hline Safe dung disposal through composting & Karnal & 14 & 8 & 22 \\
\hline
\end{tabular}

Table 3 Evaluation of social interventions introduced for dairy enterprise

\begin{tabular}{|c|c|c|c|c|}
\hline $\begin{array}{l}\text { Social intervention in } \\
\text { dairy enterprise }\end{array}$ & District & $\begin{array}{l}\text { Total perceived } \\
\text { attributes } \\
\text { ( Z1 ) }\end{array}$ & $\begin{array}{l}\text { Total perceived } \\
\text { benefits } \\
\text { ( Z2 ) }\end{array}$ & $\begin{array}{l}\text { Attributes }+ \\
\text { Benefits } \\
\text { (Total } \\
\text { Score)Z1 }+ \text { Z2 }\end{array}$ \\
\hline Village Climate Risk & Karnal & 15 & 14 & 29 \\
\hline \multirow[t]{2}{*}{ Management Committee (VCRMC) } & Yamunanagar & 16 & 14 & 30 \\
\hline & Sirsa & 14 & 13 & 27 \\
\hline Preparation of season centric dairy products for farm women & Karnal & 12 & 12 & 24 \\
\hline Women participation & Yamunanagar & 15 & 10 & 25 \\
\hline $\begin{array}{l}\text { Contingency plan forclimate change preparedness in crops } \\
\text { and fodder crops }\end{array}$ & Karnal & 15 & 10 & 25 \\
\hline
\end{tabular}


Social interventions: Four social interventions like the Village Climate Risk Management Committee (VCRMC), preparation of season centric dairy products for farm women, women participation and contingency plan for climate change preparedness in fodder crops were introduced for dairy enterprises as presented in Table 3.

Village Climate Risk Management Committee (VCRMC): Introduction of the VCRMC was mandatory under the NICRA project and introduced in the three NICRA adopted villages, one in each district. The intervention was highly rated as the total score based on the similar perceived attributes and benefits as per the feedback of farmers, were ranged from 27 to 30 in three districts. Many households of the village benefitted through the custom hiring service with active participation of women farmer members in the VCRMC.

Preparation of season centric dairy products for farm women: In the NICRA adopted village of Karnal district, women were trained on the preparation of season centric dairy products (Ponnusamy et al, 2020). The intervention was rated moderate as the total score based on perceived attributes and benefits as per feedback of farmers were 24 . They desired more women to participate and more needs of women to be addressed in the project. Similar was the view of Salula (2012), that interventions such as integration of gender and vulnerable groups related issues into climate change initiatives, ensuring that climate change researches generate gender disaggregated data on impacts and response needed to be introduced.
Women Participation: Participation of women was encouraged in the NICRA adopted village of Yamunanagar district as women were trained on the use of fungicides and fungicides were distributed only through women. The intervention was moderately rated as the total score based on perceived attributes and benefits as per feedback of farmers were 25 , securing moderate score in some sub parameters of evaluation but top score on gender equity.

Contingency plan for climate change preparedness in fodder crops: Due to unseasonal rain in the Karnal district during 2016, a contingency plan for climate change preparedness in fodder crops was developed and introduced in the NICRA adopted villages. The intervention scored moderate on number of farm families benefitted and inclusion of all farmer categories, securing a total score of 25 .

Farmer satisfaction on the Socio-Technological interventions: Since the interventions were introduced to address the climate stresses affecting dairy enterprises in the districts, it was imperative to know the perceptions of the farmers towards climate change and climate variability in their area as it would affect their acceptance and satisfaction on the interventions. The satisfaction of the farmers was rated on a four point scale of 0 to 3 , on each intervention and their reason for response is presented in Table 4.

As a result of area specific mineral mixture supplementation, the farmers of Karnal and Yamunanagar districts were highly satisfied

Table 4 Farmer satisfaction on the socio-technological interventions introduced in the NICRA adopted villages

\begin{tabular}{|c|c|c|}
\hline Socio-technological intervention & $\begin{array}{l}\text { Farmer } \\
\text { satisfaction }(0\end{array}$ & $\begin{array}{l}\text { Reason for response } \\
\text {-3) }\end{array}$ \\
\hline Area specific mineral mixture & 3 & Though it sustains high milk production, it is expensive \\
\hline supplementation & 2 & \\
\hline \multirow[t]{2}{*}{ Improved fodder crop varieties } & 3 & These are suitable, triable and more advantageous \\
\hline & 3 & $\begin{array}{l}\text { Fodder is good and stem borer does not attack HB1 \&HB2 } \\
\text { Berseem varieties in Yamunanagar district }\end{array}$ \\
\hline Vitamin E supplementation & 3 & It is triable and easy to use \\
\hline Supplementation of mustard oil & 3 & Easy to use and low input \\
\hline Silage making & 1 & $\begin{array}{l}\text { Though relative advantage is good, but, restricted land size and } \\
\text { small herd size make it uneconomical }\end{array}$ \\
\hline $\begin{array}{l}\text { Safe dung disposal through } \\
\text { composting }\end{array}$ & 2 & Though relative advantage is high, it requires some input \\
\hline VCRMC & 3 & $\begin{array}{l}\text { Through the VCRMC, many households of the village are } \\
\text { benefitted and there are three women farmer members in the VCRMC }\end{array}$ \\
\hline $\begin{array}{l}\text { Preparation of season centric dairy } \\
\text { products for farm women }\end{array}$ & 2 & $\begin{array}{l}\text { It is high in relative advantage, more women need to be } \\
\text { trained for scaling up the benefits to households }\end{array}$ \\
\hline Women participation & 2 & $\begin{array}{l}\text { The intervention is good, more needs of women may } \\
\text { be addressed. }\end{array}$ \\
\hline $\begin{array}{l}\text { Contingency plan for climate change } \\
\text { preparedness in fodder crops }\end{array}$ & 2 & $\begin{array}{l}\text { All categories of farmers were included and relative } \\
\text { advantage was also good }\end{array}$ \\
\hline
\end{tabular}


(score 3 ) by the sustained milk production during heat stress and the farmers of Sirsa district were moderately satisfied too, they found it more expensive, therefore, scored at 2. In both Karnal and Yamunanagar districts, farmers were highly satisfied with the improved fodder crop varieties, hence assigned with a top score of 3 , as the new introduced varieties were found to be triable and more advantageous. Gitz and Meybeck (2012) also reported that greater forage production, more efficient use of land resources and enhanced profitability is essential, especially considering potential degradation of climate conditions such as increased risk of drought. Farmers were slightly more satisfied with mustard oil supplementation (score 3) over Vitamin E supplementation (score 3 ) as mustard oil is not only easy to use but also demands low input.

Acceptance of silage making was low (score 1) despite its relative advantage and role in sustained production of milk during fodder scarcity periods (April-May and August-September) as; restricted land size and small herd size render it unsuitable economically. In the same way, the farmers had failed to realize the importance of safe dung disposal through composting and opined a comparatively moderate satisfaction (score 2 ) because the intervention requires some input like land and labour for digging the manure pit and turning up the contents of the pit in 15-20 days for better quality of compost.

The farmers were highly satisfied with the introduction of the Village Climate Risk Management Committee (VCRMC) and rated at 3 , in all the districts. On preparation of the season centric dairy products for farm women in adopted village of Karnal district, farmers gave a moderate satisfaction score of 2 as the intervention is high in relative advantage and more women need to be trained for scaling up the benefits to households. The farmers gave a moderate satisfaction score of 2 for women participation intervention as more needs of women may be addressed and contingency plan for climate change preparedness in fodder crops was also given a moderate rating of 2 , on the farmer satisfaction.

\section{Conclusion}

The findings of the study disclosed the importance and influence of attributes of socio-technological interventions on sustained adoption to address the climate change issues in dairy farming. While the ease of adoption and its utility emerged as a point for further refinement of introduced technologies, convincing the farmers with appropriate extension interventions hold a greater promise for encouraging a strong climate resilient and profitable dairy farming.

\section{References}

Allara M, Kugbei S, Dusunceli F, Gbehounou G (2012) Coping with Changes in Cropping Systems: Plant Pests and Seeds.FAO/OECD Workshop on Building Resilience for Adaptation to Climate Change in the Agriculture Sector pp 91-102

Chakravarty R, Upadhyay RC, Singh S, Ranga J (2012) Increasing farm and livestock resilience to climate change. NICRA Project, ICARNational Dairy Research Institute, Karnal:1-18

Cline WR (2007) Global Warming and Agriculture: Impact Estimates by Country. Finance and Development. Washington: Center for Global Development and Peterson Institute for International Economics. pp 23-27

Daze A (2011) Understanding vulnerability to climate change. CARE: Poverty, Environment and Climate Change Network (PECCN) Report:1-24

Gitz V, Meybeck A (2012) Risks, vulnerabilities and resilience in a context of climate change, in Building Resilience for Adaptation to Climate Change in the Agricultural Sector. In Proc: Joint FAO/ OECD Workshop pp 19-36

GoI (2019). Annual Report 2018-19. Department of Agriculture, Cooperation \& Farmers Welfare, Ministry of Agriculture and Farmers Welfare, Government of India pp 1-220

Huvisa TL (2012) National Climate Change Strategy. Division of Environment. United Republic of Tanzania pp1-92

Ponnusamy K, Chakravarty R, Singh, S (2019) Extension interventions in coping of farmers against effect of climate change in dairy farming. Indian J Dairy Sci 72: 430-436.

Ponnusamy K, Oberoi PS, Kumar A (2020) Impact analysis of women centric technological interventions in rural dairy farming. Indian $\mathrm{J}$ Dairy Sci 73: 365-370

Ponnusamy K, Pachaiyappan K (2018) Strengthening extension research in animal husbandry: review of issues and strategies. Indian J Anim Sci 88: 137-143

Salula SB (2012) Climate Change Strategy. Division of Environment, United Republic of Tanzania. pp 1-92 